\title{
Prediabetes Is Associated with an Increased Risk of Testosterone Deficiency, Independent of Obesity and Metabolic Syndrome
}

\author{
Chen-Hsun Ho ${ }^{1,2}$, Hong-Jeng Yu², Chih-Yuan Wang ${ }^{3}$, Fu-Shan Jaw ${ }^{4}$, Ju-Ton Hsieh², Wan-Chung Liao5, \\ Yeong-Shiau $\mathrm{Pu}^{2}$, Shih-Ping $\mathrm{Liu}^{2^{*}}$
}

1 Graduate Institute of Clinical Medicine, College of Medicine, National Taiwan University, Taipei, Taiwan, 2 Department of Urology, National Taiwan University Hospital and College of Medicine, Taipei, Taiwan, 3 Department of Internal Medicine, National Taiwan University Hospital and College of Medicine, Taipei, Taiwan, 4 Institute of Biomedical Engineering, National Taiwan University, Taipei, Taiwan, 5 Health Management Center, National Taiwan University Hospital, Taipei, Taiwan

\begin{abstract}
Objective: The association between type 2 diabetes and low testosterone has been well recognized. However, testosterone levels in men with prediabetes have been rarely reported. We aimed to investigate whether prediabetes was associated with an increased risk of testosterone deficiency.

Methods: This study included 1,306 men whose sex hormones was measured during a medical examination. Serum total testosterone and sex hormone-binding globulin were measured; free and bioavailable testosterone concentrations were calculated by Vermeulen's formula. Prediabetes was defined by impaired fasting glucose (IFG), impaired postprandial glucose (IPG), or glycated hemoglobin (HbA1c) 5.7\%-6.4\%. Logistic regression was performed to obtain the odds ratios (OR) for subnormal total testosterone $(<300 \mathrm{ng} / \mathrm{dL}$ ) or free testosterone $(<6 \mathrm{ng} / \mathrm{dL})$ in prediabetic and diabetic men compared with normoglycemic individuals, while adjusting for age, BMI, waist circumference, and metabolic syndrome (MetS).

Results: Normoglycemia, prediabetes, and diabetes were diagnosed in 577 (44.2\%), 543 (41.6\%), and 186 (14.2\%) men, respectively. Prediabetes was associated with an increased risk of subnormal total testosterone compared to normoglycemic individuals (age-adjusted $\mathrm{OR}=1.87 ; 95 \% \mathrm{Cl}=1.38-2.54$ ). The risk remained significant in all multivariate analyses. After adjusting for MetS, the OR in prediabetic men equals that of diabetic patients (1.49 versus 1.50). IFG, IPG, and $\mathrm{HbA} 1 \mathrm{c} 5.7 \%-6.4 \%$ were all associated with an increased risk of testosterone deficiency, with different levels of significance in multivariate analyses. However, neither prediabetes nor diabetes was associated with subnormal free testosterone in multivariate analyses.

Conclusions: Prediabetes is associated with an increased risk of testosterone deficiency, independent of obesity and MetS. After adjusting for MetS, the risk equals that of diabetes. Our data suggest that testosterone should be measured routinely in men with prediabetes.

Citation: Ho C-H, Yu H-J, Wang C-Y, Jaw F-S, Hsieh J-T, et al. (2013) Prediabetes Is Associated with an Increased Risk of Testosterone Deficiency, Independent of Obesity and Metabolic Syndrome. PLoS ONE 8(9): e74173. doi:10.1371/journal.pone.0074173

Editor: Harpal Singh Randeva, University of Warwick - Medical School, United Kingdom

Received April 4, 2013; Accepted July 27, 2013; Published September 12, 2013

Copyright: @ $2013 \mathrm{Ho}$ et al. This is an open-access article distributed under the terms of the Creative Commons Attribution License, which permits unrestricted use, distribution, and reproduction in any medium, provided the original author and source are credited.

Funding: The authors have no funding or support to report.

Competing interests: The authors have declared that no competing interests exist.

*E-mail: spliu@ntuh.gov.tw
\end{abstract}

\section{Introduction}

Type 2 diabetes is associated with testosterone deficiency (TD), as cross-sectional studies have shown approximately $25 \%$ to $40 \%$ of diabetic men have low testosterone [1-3] and longitudinal studies have demonstrated that men with low testosterone are at a greater risk of future development of type 2 diabetes [4-7]. While the mechanisms are not fully understood, current evidence suggests that the causative relationship between TD and diabetes might be bidirectional, or even multidirectional and interrelated with obesity, metabolic syndrome (MetS), sex hormone-binding globulins (SHBG), and other factors $[8,9]$.

Prediabetes is a condition in which blood glucose level is higher than normal but does not reach the level of diabetes. Most diabetes organizations define prediabetes by impaired fasting glucose (IFG) and impaired glucose tolerance (IGT), while the American Diabetes Association (ADA) proposes that 
a glycated hemoglobin $(\mathrm{HbA} 1 \mathrm{c})$ of $5.7 \%$ to $6.4 \%$ should be also considered one of the criteria [10]. Prediabetes is characterized by increased insulin resistance and $\beta$-cell dysfunction, and is considered to precede the development of type 2 diabetes [11]. Data from non-diabetic men have revealed an inverse association between insulin resistance and testosterone concentrations [12-14]. This raised the question whether prediabetes, a state of increased insulin resistance, is also associated with low testosterone. However, few studies have investigated sex hormone levels in men with prediabetes, and the risk of TD in men with prediabetes has not been reported.

The present study aimed to investigate whether men with prediabetes were at an increased the risk of TD. Furthermore, as prediabetes is closely linked to obesity and MetS, both of which are associated with TD [8], we also explored whether the relationship between prediabetes and TD, if present, was independent of these factors.

\section{Materials and Methods}

\section{Study design and subjects}

This is a cross-sectional study. We obtained the data from the database of Health Management Center, National Taiwan University Hospital. In 2009, a total of 1,339 men received sex hormone measurement as part of their medical examination. We excluded those who received testosterone supplement $(n=3)$ or received androgen deprivation therapy for prostate cancer $(n=7)$ and those whose data were incompletely recorded $(n=23)$. The remaining 1,306 constituted the study subjects of the current study. The study protocol was approved by the institutional review board (IRB) of National Taiwan University Hospital (201207058RIC). The IRB waived the need for consent, since all data were de-identified and the investigators could not recognize the identity of any subject.

\section{Collection of basic data}

All participants completed a self-administered questionnaire to collect their basic demographic data and medical histories. All subjects were then interviewed by an internal medicine physician, and a detailed physical examination was performed.

\section{Laboratory tests and sex hormone parameters}

Two blood samples were collected from each subject: the first sample was collected after an overnight fast between 8 am and $10 \mathrm{am}$, and was used to measure fasting blood glucose, sex hormones, and other biochemical data; the second blood sample was collected two hours after a standard lunch and was used to measure the postprandial glucose. Total testosterone and SHBG were measured by chemiluminescent microparticle immunoassay using the Architect Testosterone and SHBG Reagent kits (Abbott Laboratories, Chicago, IL), respectively. Free testosterone was calculated by the formula proposed by Vermeulen [15]. The free testosterone concentration calculated by this formula correlate well with the concentrations measured by equilibrium dialysis and ammonium sulfate precipitation, respectively [15], and the formula has been widely adopted by other investigators $[1,2,13]$. Low total testosterone was defined by total testosterone $<300 \mathrm{ng} / \mathrm{dL}$ [16-18], and low free testosterone was defined by free testosterone $<6 \mathrm{ng} / \mathrm{dL}$.

\section{Diagnoses of prediabetes, diabetes, and metabolic syndrome}

Prediabetes was diagnosed if any of the following criteria was met: 1) fasting glucose $100-125 \mathrm{mg} / \mathrm{dL}$ (IFG), 2) two-hour postprandial glucose $140-199 \mathrm{mg} / \mathrm{dL}$ (IPG), or 3) $\mathrm{HbA} 1 \mathrm{c}$ $5.7 \%-6.4 \%$. The definition was adopted from the recommendations of the ADA [10], with the exception that twohour postprandial glucose was used to replace a standard oral glucose tolerance test (OGTT) [19,20]. Diabetes was diagnosed if the patient had a prior history of diabetes or if the glycemic variables reached the criteria of diabetes: fasting glucose $\geq 126 \mathrm{mg} / \mathrm{dL}$, two-hour postprandial glucose $\geq 200$ $\mathrm{mg} / \mathrm{dL}$, or $\mathrm{HbA} 1 \mathrm{c} \geq 6.5 \%$ [10]. The diagnosis of MetS was based on the modified ATP III criteria for Asians [21], and one was considered to have MetS if any three of the following were met: 1) waist circumference $>90 \mathrm{~cm}, 2$ ) triglycerides $>150$ $\mathrm{mg} / \mathrm{dL}, 3$ ) high-density lipoprotein cholesterol $<40 \mathrm{mg} / \mathrm{dL}, 4$ ) blood pressure $>130 / 85 \mathrm{mmHg}$, and 5) fasting glucose $>100$ $\mathrm{mg} / \mathrm{dL}$.

\section{Statistical analyses}

Continuous data are presented as the mean \pm standard deviation (SD), and categorical data are presented as count and percentage (\%). Logistic regression was performed to obtain the odds ratios for TD in men with prediabetes and diabetes compared with those with normoglycemia. Five statistical models were used for multivariate analyses: Model 1, adjusted for age; Model 2, adjusted for age and body mass index (BMI); Model 3, adjusted for age and waist circumference; Model 4, adjusted for age and the number of MetS components; Model 5, adjusted for age and MetS. Multiple linear regression was performed to assess the association between total and free testosterone and prediabetes or diabetes. All statistical assessments were twotailed, and a p-value of $<0.05$ was considered significant. All statistical procedures were performed using SPSS 17.0 (SPSS Inc., Chicago, IL).

\section{Results}

Among the 1,306 male participants, 577 (44.1\%) were normoglycemic, $543(41.5 \%)$ were prediabetic, and 186 $(14.4 \%)$ were diabetic. The characteristics of the three groups are listed in Table 1. The mean ages of the three groups were $52.6 \pm 8.8,55.8 \pm 8.5$, and $59.7 \pm 7.9$ years $(P<0.001)$; the mean BMls were $24.4 \pm 3.0,25.2 \pm 3.1$, and $25.6 \pm 3.3 \mathrm{~kg} / \mathrm{m}^{2}$ $(P<0.001)$; the mean waist circumferences were $86.6 \pm 7.4$, $89.2 \pm 7.5$, and $90.6 \pm 8.7 \mathrm{~cm}(P<0.001)$. Metabolic syndrome was present in $12.9 \%, 35.4 \%$, and $60.5 \%$ of the patients $(\mathrm{P}<0.001)$, and the mean number of MetS components was 1.1 $\pm 1.1,2.0 \pm 1.3$, and $2.8 \pm 1.3(\mathrm{P}<0.001)$. The mean testosterone concentration and the prevalence of subnormal testosterone are listed in Table 2.

The age-adjusted odds ratio for subnormal total testosterone was $1.87(95 \%$ confidence interval [Cl]: 1.38-2.54) in 
Table 1. Characteristics of the 1,306 male subjects.

\begin{tabular}{llll}
\hline & & & \\
\hline & NGT & Prediabetes & Diabetes \\
\hline & $\mathrm{n}=577$ & $\mathrm{n}=543$ & $\mathrm{n}=186$ \\
Age (years) & $52.6 \pm 8.6$ & $55.8 \pm 8.5$ & $59.7 \pm 7.9$ \\
Age range (years) & $51.8-53.3$ & $55.1-56.6$ & $58.6-60.9$ \\
BMI (kg/m²) & $24.4 \pm 3.0$ & $25.2 \pm 3.1$ & $25.6 \pm 3.3$ \\
BMI range (kg/m2) & $24.2-24.6$ & $25.0-25.5$ & $25.1-26.0$ \\
Waist (cm) & $86.6 \pm 7.4$ & $89.2 \pm 7.5$ & $90.6 \pm 8.7$ \\
Waist >=90 cm (\%) & $32.9 \%$ & $47.7 \%$ & $50.3 \%$ \\
Fasting glucose (mg/dL) & $89.3 \pm 5.3$ & $98.2 \pm 8.9$ & $123.4 \pm 31.6$ \\
Postprandial glucose (mg/dL) & $99.5 \pm 18.9$ & $127.9 \pm 31.2$ & $203.0 \pm 66.0$ \\
\hline HbA1c (\%) & $5.34 \pm 0.23$ & $5.71 \pm 0.28$ & $6.73 \pm 1.09$ \\
HbA1c range (\%) & $5.32-5.36$ & $5.69-5.74$ & $6.57-6.88$ \\
\hline Triglyceride (mg/dL) & $122.5 \pm 67.7$ & $143.9 \pm 77.5$ & $158.0 \pm 105.2$ \\
TG >=150 mg/dL (\%) & $26.2 \%$ & $38.3 \%$ & $41.4 \%$ \\
Cholesterol (mg/dL) & $202.4 \pm 33.3$ & $208.2 \pm 33.8$ & $195.2 \pm 41.0$ \\
\hline LDL (mg/dL) & $119.3 \pm 30.1$ & $124.5 \pm 30.7$ & $113.4 \pm 36.5$ \\
\hline HDL (mg/dL) & $47.4 \pm 10.3$ & $45.7 \pm 11.1$ & $44.1 \pm 10.6$ \\
HDL<40 mg/dL (\%) & $22.9 \%$ & $29.1 \%$ & $40.3 \%$ \\
\hline Systolic pressure (mmHg) & $117.4 \pm 17.0$ & $122.3 \pm 14.9$ & $124.3 \pm 14.7$ \\
Diastolic pressure (mmHg) & $69.5 \pm 11.5$ & $72.1 \pm 10.0$ & $71.8 \pm 9.6$ \\
Hypertension (\%) & $29.3 \%$ & $44.9 \%$ & $60.8 \%$ \\
\hline Num. of MetS components & $1.1 \pm 1.1$ & $2.0 \pm 1.3$ & $2.8 \pm 1.3$ \\
\hline MetS (\%) & $12.9 \%$ & $35.4 \%$ & $60.5 \%$ \\
\hline & & &
\end{tabular}

doi: 10.1371/journal.pone.0074173.t001

prediabetic men and $2.38(95 \% \mathrm{Cl}: 1.57-3.60)$ in diabetic patients (Model 1 in Table 3). The odds ratios in prediabetic men remained significant in multivariate analyses that further adjusted for BMI, waist circumference, the number of MetS components, and MetS (Models 2-5 in Table 3). After adjustment for MetS, the odds ratio for subnormal total testosterone in prediabetic men was 1.49 (95\% Cl: 1.08-2.06), almost equal to the odds ratio of 1.50 in diabetic patients (Model 5 in Table 3).

The presence of IFG, IPG, and HbA1c 5.7\%-6.4\% were all significantly associated with an increased risk of TD after adjustment for age (Model 1 in Table 3). In multivariate analyses, HbA1c $5.7 \%-6.4 \%$ remained significant in models that further adjusted for BMI, waist circumference, the number of MetS components, or MetS (Models 2-5 in Table 3). IFG was significant in most multivariate analyses (Models 2 to 4), but was no longer significant after adjustment for MetS (Model 5 in Table 3). However, IPG was not significant after any further adjustments (Models 2-5 in Table 3).

Figure 1 demonstrates the age-adjusted odds ratios for subnormal total testosterone in various conditions of hyperglycemia as classified by fasting glucose, postprandial glucose, and HbA1c. Compared to those with normoglycemia, men with isolated IFG, HbA1c 5.7\%-6.4\% (with or without elevations in fasting or postprandial glucose), newly detected diabetes, or previously diagnosed diabetes were all at an increased risk for TD.

Table 4 shows the adjusted odds ratios for subnormal free testosterone in various glycemic groups. Neither prediabetes nor diabetes was associated with an increased risk of subnormal free testosterone after adjustment for age, BMI, waist circumference, the number of MetS, or MetS. IFG, IPG, or HbA1c $5.7 \%-6.4 \%$ was not associated with subnormal free testosterone in all multivariate analyses.

The association between testosterone and prediabetes or diabetes was also examined with multiple linear regression (Tables 5 and 6). Both prediabetes and diabetes were significant associated with total testosterone, independent of age, BMI, waist circumference, the number of MetS components, and MetS. The effect of prediabetes on total testosterone concentration was similar to that of diabetes (Model 5 in Table 5). On the contrary, the association between free testosterone and prediabetes was not significant in all multivariate analyses (Table 6).

\section{Discussion}

In the present study, we aimed to elucidate whether men with prediabetes had a greater risk for TD, while adjusting for obesity and MetS. The major findings are as follows: 1) prediabetes was associated with an increased risk of subnormal total testosterone, and the risk remained significant in multivariate analyses that adjusted for age, BMI, waist circumferences, the number of MetS components, and MetS; 2) after adjustment for MetS, the risk for subnormal total testosterone in men with prediabetes was equal to that in men with diabetes; 3) neither prediabetes nor diabetes was associated with subnormal free testosterone in multivariate analyses.

While there is a substantial body of evidence demonstrating the association between low testosterone and diabetes [1-7], few studies have reported the androgen status of men with prediabetes, which is considered the preceding stage of overt diabetes. In a study including 221 non-diabetic men, total testosterone was inversely associated with fasting glucose level and insulin resistance, and the association was independent of total body fat or abdominal fat [13]. Moreover, the Rancho Bernardo Study evaluated the sex hormone levels in 775 men and showed that men with IFG or IGT had lower total testosterone than those with normal glucose tolerance, after adjustment for age and BMI [22]. More recently, Corona et al. [23]evaluated the impact of IFG on sexual health in a consecutive 3,451 men attending the clinic for sexual dysfunction, and found that IFG increases the risk of severe erectile dysfunction, reduced penile flow, and overt hypogonadism [23]. Our findings in large part concur with the results of the previous studies, but there are some difference and several novel findings. First, the present study adopted a more updated definition of prediabetes, in which an $\mathrm{HbA} 1 \mathrm{c}$ of $5.7 \%-6.4 \%$ was incorporated in the criteria of prediabetes and was proved as a significant risk factor for TD. To our knowledge, it is the first study reporting the association between $\mathrm{HbA} 1 \mathrm{c}$ and testosterone in non-diabetic population. Second, we made a more comprehensive multivariate analysis, which adjusted for not only age but also several factors associated with obesity and MetS. The risk was reduced but remained significant after adjustment for BMI (a proxy of total body fat) or waist circumference (a proxy of visceral abdominal 
Table 2. Mean testosterone concentrations and prevalence of testosterone deficiency within subgroups.

\begin{tabular}{|c|c|c|c|c|c|c|c|}
\hline & & & NGT & Prediabetes & Diabetes & Total & $P$ value \\
\hline \multirow[t]{5}{*}{ All } & & Case number & 577 & 543 & 186 & 1306 & \\
\hline & & mean TT, ng/dL & $440.5 \pm 152.2$ & $397.2 \pm 133.6$ & $381.2 \pm 132.9$ & $414.1 \pm 143.9$ & $<0.001$ \\
\hline & & $\mathrm{TT}<300 \mathrm{ng} / \mathrm{dL}, \mathrm{N}(\%)$ & $88(15.3 \%)$ & $131(24.1 \%)$ & $51(27.4 \%)$ & $270(20.7 \%)$ & $<0.001$ \\
\hline & & mean FT, ng/dL & $8.6 \pm 2.6$ & $8.1 \pm 2.4$ & $7.7 \pm 2.6$ & $8.3 \pm 2.6$ & $<0.001$ \\
\hline & & FT <6 ng/dL, N(\%) & 77 (13.3\%) & $97(17.9 \%)$ & $37(19.9 \%)$ & $211(16.2 \%)$ & 0.004 \\
\hline \multirow[t]{15}{*}{ Age } & 50 & Case number & 216 & 117 & 17 & 350 & \\
\hline & & mean $\mathrm{TT}, \mathrm{ng} / \mathrm{dL}$ & $438.0 \pm 146.7$ & $383.5 \pm 123.3$ & $331.2 \pm 134.6$ & $414.6 \pm 141.9$ & $<0.001$ \\
\hline & & $\mathrm{TT}<300$ ng/dL, N(\%) & $38(17.6 \%)$ & $32(27.4 \%)$ & $8(47.1 \%)$ & $78(22.3 \%)$ & 0.005 \\
\hline & & mean FT, ng/dL & $9.1 \pm 2.7$ & $8.7 \pm 2.5$ & $7.3 \pm 2.6$ & $8.9 \pm 2.6$ & 0.018 \\
\hline & & FT <6 ng/dL, N(\%) & $21(9.7 \%)$ & $13(11.1 \%)$ & $5(29.4 \%)$ & $39(11.1 \%)$ & 0.046 \\
\hline & $50-59$ & Case number & 252 & 251 & 80 & 583 & \\
\hline & & mean $\mathrm{TT}, \mathrm{ng} / \mathrm{dL}$ & $433.6 \pm 159.2$ & $395.9 \pm 130.5$ & $394.7 \pm 146.3$ & $412.0 \pm 146.6$ & 0.008 \\
\hline & & $\mathrm{TT}<300 \mathrm{ng} / \mathrm{dL}, \mathrm{N}(\%)$ & $38(15.1 \%)$ & $58(23.1 \%)$ & $21(26.3 \%)$ & $117(20.1 \%)$ & 0.027 \\
\hline & & mean FT, ng/dL & $8.4 \pm 2.7$ & $8.3 \pm 2.4$ & $8.2 \pm 3.1$ & $8.3 \pm 2.6$ & 0.85 \\
\hline & & FT <6 ng/dL, N(\%) & $39(15.5 \%)$ & $44(17.5 \%)$ & $14(17.5 \%)$ & $97(16.6 \%)$ & 0.806 \\
\hline & 60 & Case number & 109 & 175 & 89 & 373 & \\
\hline & & mean $\mathrm{TT}, \mathrm{ng} / \mathrm{dL}$ & $461.6 \pm 145.6$ & $408.3 \pm 143.9$ & $378.7 \pm 118.1$ & $416.8 \pm 141.8$ & $<0.001$ \\
\hline & & $\mathrm{TT}<300 \mathrm{ng} / \mathrm{dL}, \mathrm{N}(\%)$ & $12(11 \%)$ & $41(23.4 \%)$ & $22(24.7 \%)$ & $75(20.1 \%)$ & 0.018 \\
\hline & & mean FT, ng/dL & $8.0 \pm 2.4$ & $7.5 \pm 2.3$ & $7.3 \pm 2.0$ & $7.6 \pm 2.3$ & 0.111 \\
\hline & & FT <6 ng/dL, N(\%) & $17(15.6 \%)$ & $40(22.9 \%)$ & $18(20.2 \%)$ & $75(20.1 \%)$ & 0.332 \\
\hline \multirow[t]{15}{*}{ BMI } & 24 & Case number & 248 & 182 & 58 & 488 & \\
\hline & & mean TT, ng/dL & $472.1 \pm 156.3$ & $437.0 \pm 149.0$ & $428.9 \pm 155.1$ & $453.9 \pm 154.3$ & 0.028 \\
\hline & & $\mathrm{TT}<300 \mathrm{ng} / \mathrm{dL}, \mathrm{N}(\%)$ & $24(9.7 \%)$ & $30(16.5 \%)$ & $9(15.5 \%)$ & $63(12.9 \%)$ & 0.094 \\
\hline & & mean FT, ng/dL & $8.7 \pm 2.8$ & $8.4 \pm 2.8$ & $8.0 \pm 3.5$ & $8.5 \pm 2.9$ & 0.223 \\
\hline & & FT <6 ng/dL, N(\%) & $34(13.7 \%)$ & $32(17.6 \%)$ & $15(25.9 \%)$ & $81(16.6 \%)$ & 0.074 \\
\hline & $24-26.9$ & Case number & 229 & 223 & 73 & 525 & \\
\hline & & mean $\mathrm{TT}, \mathrm{ng} / \mathrm{dL}$ & $426.9 \pm 150.3$ & $392.7 \pm 126.2$ & $380.8 \pm 116.7$ & $405.9 \pm 137.1$ & 0.007 \\
\hline & & $\mathrm{TT}<300 \mathrm{ng} / \mathrm{dL}, \mathrm{N}(\%)$ & $43(18.8 \%)$ & $59(26.5 \%)$ & $16(21.9 \%)$ & $118(22.5 \%)$ & 0.147 \\
\hline & & mean FT, ng/dL & $8.5 \pm 2.6$ & $8.1 \pm 2.3$ & $7.9 \pm 2.1$ & $8.3 \pm 2.4$ & 0.079 \\
\hline & & FT <6 ng/dL, N(\%) & $28(12.2 \%)$ & $42(18.8 \%)$ & $9(12.3 \%)$ & $79(15 \%)$ & 0.114 \\
\hline & $\geqq 27$ & Case number & 100 & 138 & 55 & 293 & \\
\hline & & mean $\mathrm{TT}, \mathrm{ng} / \mathrm{dL}$ & $393.4 \pm 128.7$ & $352.1 \pm 105.9$ & $331.6 \pm 109.5$ & $362.3 \pm 116.8$ & 0.002 \\
\hline & & $\mathrm{TT}<300 \mathrm{ng} / \mathrm{dL}, \mathrm{N}(\%)$ & $21(21 \%)$ & $42(30.4 \%)$ & $26(47.3 \%)$ & $89(30.4 \%)$ & 0.003 \\
\hline & & mean FT, ng/dL & $8.4 \pm 2.5$ & $7.8 \pm 2.1$ & $7.1 \pm 2.1$ & $7.9 \pm 2.3$ & 0.003 \\
\hline & & FT <6 ng/dL, N(\%) & $15(15 \%)$ & $23(16.7 \%)$ & $13(23.6 \%)$ & $51(17.4 \%)$ & 0.379 \\
\hline \multirow[t]{10}{*}{ MS } & negative & Case number & 500 & 351 & 73 & 924 & \\
\hline & & mean $\mathrm{TT}, \mathrm{ng} / \mathrm{dL}$ & $451.2 \pm 151.5$ & $421.7 \pm 143.1$ & $415.3 \pm 122.9$ & $437.2 \pm 146.9$ & 0.006 \\
\hline & & $\mathrm{TT}<300 \mathrm{ng} / \mathrm{dL}, \mathrm{N}(\%)$ & $63(12.6 \%)$ & $69(19.7 \%)$ & $9(12.3 \%)$ & $141(15.3 \%)$ & 0.014 \\
\hline & & mean FT, ng/dL & $8.7 \pm 2.7$ & $8.3 \pm 2.6$ & $7.8 \pm 2.5$ & $8.5 \pm 2.6$ & 0.015 \\
\hline & & FT <6 ng/dL, N(\%) & $62(12.4 \%)$ & $62(17.7 \%)$ & $17(23.3 \%)$ & $141(15.3 \%)$ & 0.015 \\
\hline & positive & Case number & 74 & 192 & 112 & 378 & \\
\hline & & mean TT, ng/dL & $365.3 \pm 132.6$ & $352.5 \pm 99.8$ & $359.4 \pm 135.5$ & $357.1 \pm 117.8$ & 0.707 \\
\hline & & $\mathrm{TT}<300 \mathrm{ng} / \mathrm{dL}, \mathrm{N}(\%)$ & $24(32.4 \%)$ & $62(32.3 \%)$ & $42(37.5 \%)$ & $128(33.9 \%)$ & 0.625 \\
\hline & & mean FT, ng/dL & $8.0 \pm 2.3$ & $7.7 \pm 2.1$ & $7.7 \pm 2.7$ & $7.8 \pm 2.3$ & 0.662 \\
\hline & & FT $<6$ ng/dL, N(\%) & $14(18.9 \%)$ & $35(18.2 \%)$ & $20(17.9 \%)$ & $69(18.3 \%)$ & 0.983 \\
\hline
\end{tabular}

$\mathrm{P}$ value compares continuous variables with $\mathrm{t}$ test and categorical variables with chi-square test.

TT, total testosterone; FT, free testosterone; MS, metabolic syndrome; NS, not significant

doi: 10.1371/journal.pone.0074173.t002

fat), suggesting a mechanism other than the consumption by fat is involved in the relationship between TD and prediabetes or diabetes. And we also found that men with prediabetes were at virtually the same risk of subnormal total testosterone as men with diabetes after adjustment for MetS. Third, while the
Rancho Bernardo Study exclusively enrolled men aged over 55 years (mean age: 71.9 years), the present study included male participants aged 24 to 86 years (mean age: 54.9 years). The association between prediabetes and testosterone TD could therefore be applied to men over a wider age range. As the 
Table 3. Adjusted odds ratios for total testosterone $<300 \mathrm{ng} / \mathrm{dL}$ in multivariate analyses.

\begin{tabular}{|c|c|c|c|c|c|}
\hline & Model 1 & Model 2 & Model 3 & Model 4 & Model 5 \\
\hline & OR & OR & OR & OR & OR \\
\hline Normoglycemia & 1.00 & 1.00 & 1.00 & 1.00 & 1.00 \\
\hline Prediabetes & $1.87(1.38,2.54)^{+}$ & $1.69(1.24,2.30)^{\sharp}$ & $1.63(1.19,2.23)^{\sharp}$ & $1.50(1.09,2.06)^{\star}$ & $1.49(1.08,2.06)^{*}$ \\
\hline Diabetes & $2.38(1.57,3.60)^{+}$ & $2.03(1.33,3.09)^{\sharp}$ & $1.90(1.24,2.92)^{\sharp}$ & $1.62(1.05,2.50)^{\star}$ & $1.50(0.96,2.35)$ \\
\hline \multicolumn{6}{|l|}{ FPG (mg/dL) } \\
\hline$<100$ & 1.00 & 1.00 & 1.00 & 1.00 & 1.00 \\
\hline $100-125$ & $1.82(1.32,2.50)^{+}$ & $1.66(1.20,2.30)^{\#}$ & $1.52(1.09,2.11)^{\star}$ & $1.45(1.03,2.02)^{*}$ & $1.19(0.83,1.22)$ \\
\hline$>=126$ or known DM & $1.99(1.30,3.03)^{\#}$ & $1.71(1.11,2.64)^{*}$ & $1.61(1.04,2.49)^{\star}$ & $1.40(0.9,2.18)$ & $1.22(0.77,1,93)$ \\
\hline \multicolumn{6}{|l|}{ PPG (mg/dL) } \\
\hline$<140$ & 1.00 & 1.00 & 1.00 & 1.00 & 1.00 \\
\hline 140-199 & $1.46(1.04,2.07)^{*}$ & $1.42(1.00,2.02)$ & $1.40(0.98,1.99)$ & $1.22(0.85,1.75)$ & $1.23(0.86,1.75)$ \\
\hline$>=200$ or known DM & $1.67(1.11,2.52)^{*}$ & $1.53(1.01,2.33)^{*}$ & $1.47(0.96,2.25)$ & $1.29(0.85,1.98)$ & $1.16(0.75,1.78)$ \\
\hline \multicolumn{6}{|l|}{ HbA1c (\%) } \\
\hline$<5.7$ & 1.00 & 1.00 & 1.00 & 1.00 & 1.00 \\
\hline $5.7-6.4$ & $1.77(1.31,2.39)^{+}$ & $1.56(1.15,2.12)^{\sharp}$ & $1.48(1.08,2.02)^{\star}$ & $1.44(1.05,1.97)^{\star}$ & $1.46(1.07,2.00)^{*}$ \\
\hline$>=6.5$ or known DM & $2.19(1.46,3.30)^{+}$ & $1.83(1.20,2.79)^{\sharp}$ & $1.69(1.10,2.59)^{\star}$ & $1.51(0.99,2.33)$ & $1.50(0.91,2.18)$ \\
\hline
\end{tabular}

FPG: fasting plasma glucose; PPG: postprandial plasma glucose

Model 1: adjusted for age

Model 2: adjusted for age and BMI

Model 3: adjusted for age and waist circumference

Model 4: adjusted for age and numbers of MetS components

Model 5: adjusted for age and MetS

*: $p<0.05 ; \#:$ p $<0.01 ;+:<0.001$

doi: $10.1371 /$ journal.pone. $0074173 . t 003$

Endocrine Society recommends routine measurement of testosterone in all men with type 2 diabetes, the substantially increased risk of TD shown in the present study suggests the measurement should be performed earlier, as at the stage of prediabetes.

The definition of prediabetes differs among health organizations. It is generally composed of IFG and IGT, although different cutoff values to define IFG were adopted by the ADA and the World Health Organization (WHO) $(100 \mathrm{mg} / \mathrm{dL}$ or $110 \mathrm{mg} / \mathrm{dL}$, respectively) [10]. Greater controversy exists over whether $\mathrm{HbA} 1 \mathrm{c}$ of $5.7 \%$ to $6.4 \%$ should be considered as prediabetes. Currently, an intermediate $\mathrm{HbA} 1 \mathrm{c}$ range is considered prediabetes by the ADA [10], but not by the WHO. It has to be noted that the selection of glycemic measures and cutoff values to define prediabetes is based on the risk of future development of overt diabetes. However, elevations in fasting and postprandial glucose levels may be caused by different mechanisms and may represent distinct stages of diabetes development [11,24-27]. Prediabetes identified by IFG, IGT, or an intermediate $\mathrm{HbA} 1 \mathrm{c}$ range may represent different population and is associated with different features of metabolic derangement $[28,29]$. Moreover, fasting and postprandial hyperglycemia have been shown to be associated with different levels of risk of disease, such as cardiovascular events and mortality [30,31]. Intrigued by these findings, we further examined whether the risk of TD might differ in men with IFG, IPG, or HbA1c $5.7 \%-6.4 \%$. Our data show that $\mathrm{HbA} 1 \mathrm{c}$ appeared to be a stronger predictor of subnormal total testosterone, and it remained significant across all multivariate analyses. Men with $\mathrm{HbA} 1 \mathrm{c} 5.7 \%-6.4 \%$, with or without fasting or postprandial hyperglycemia, were at a significantly increased risk of subnormal total testosterone. IFG was also a reliable predictor in most multivariate adjustments, and loss of significance was only observed after adjustment for MetS. An isolated IFG, even with $\mathrm{HbA} 1 \mathrm{c}$ of $<5.7 \%$, was significantly associated with an increased risk of subnormal total testosterone. In contrast, compared with fasting glucose or $\mathrm{HbA1c}$ levels, postprandial glucose was only weakly associated with TD in the present study. Although postprandial glucose has been used in lieu of a standard OGTT to define prediabetes in the literature [19], the clinical application of postprandial glucose has been controversial due to low reproducibility and a lack of a standardized method of measurement [32-34]. Postprandial hyperglycemia has been considered as a surrogate of a much more complex series of metabolic events that occur in the postprandial period [33]. These facts support our finding that the relationship between postprandial hyperglycemia and testosterone is confounded by obesity or MetS, or can be explained by an overlap with fasting hyperglycemia or elevated $\mathrm{HbA} 1 \mathrm{c}$. Nonetheless, from a clinical perspective, men with elevated fasting glucose, postprandial 
Total Testosterone $<300 \mathrm{ng} / \mathrm{dL}$

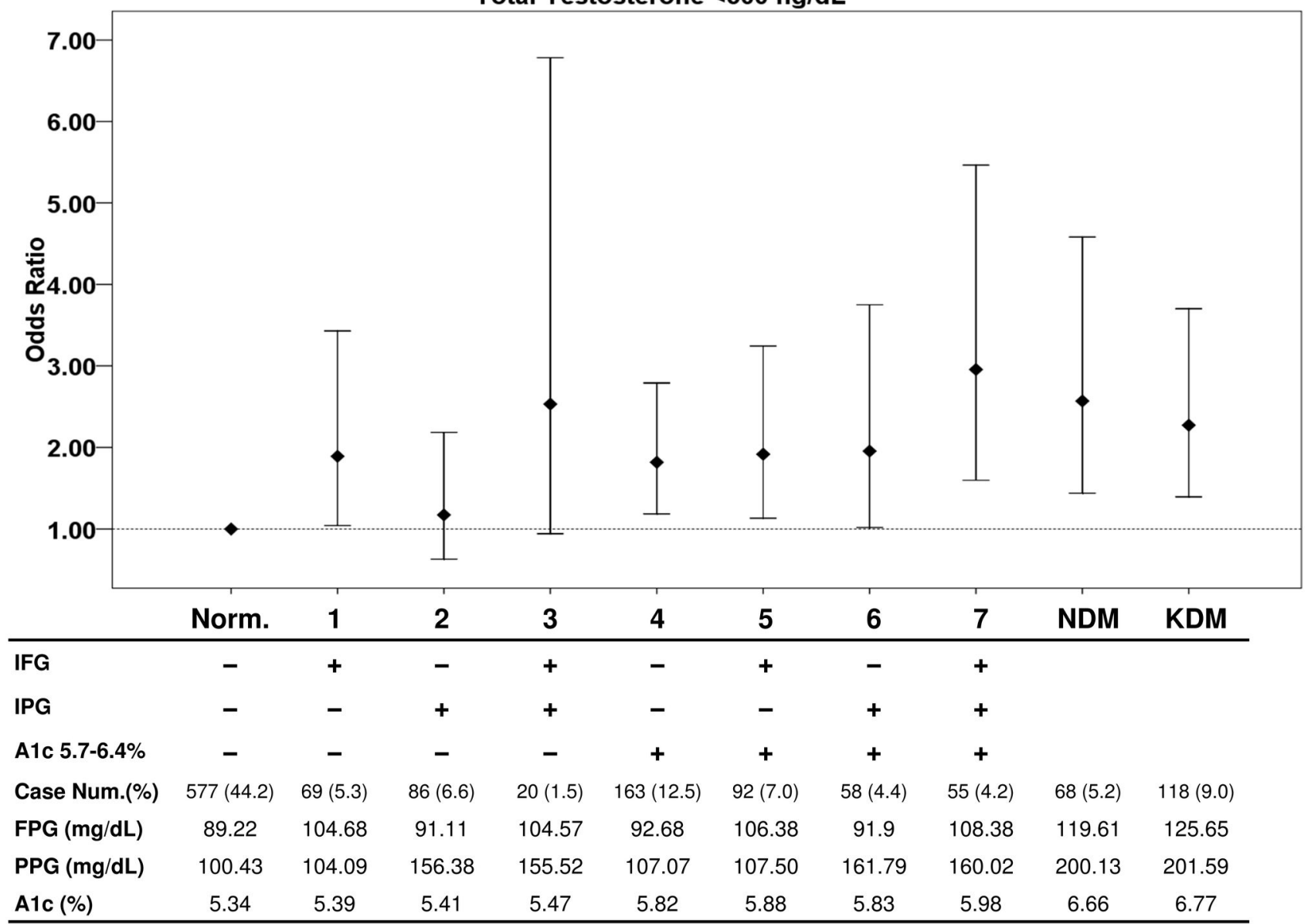

All were adjsuted for age; Groups 1-7 denote the various conditions of prediabetes; Norm.: normoglycemia; NDM: newly detected diabetes; KDM: known diabetes; IFG: Impaired fasting glucose; IPG: Impaired postprandial glucose; FPG: fasting plasma glucose; PPG: 2-hour postprandial glucose.

Figure 1. Age-adjusted Odds Ratios for Total Testosterone $<\mathbf{3 0 0} \mathbf{n g} / \mathbf{d L}$ in Various Conditions of Hyperglycemia. doi: 10.1371/journal.pone.0074173.g001

glucose, or $\mathrm{HbA1c}$, with or without other metabolic disorder, should be tested for TD.

Total testosterone is composed of free (2-3\%), albuminbound (20-40\%), and SHBG-bound testosterone $(60-80 \%)$. While the present study found that prediabetes was significantly associated with subnormal total testosterone, its association with free or bioavailable testosterone was not significant. This finding is supported by most but not all of the previous studies. In the Rancho Bernardo Study, the total but not the bioavailable testosterone concentration correlated with the insulin resistance and the risk of subsequent development of type 2 diabetes in middle-aged men after adjustment for age, BMI, or systolic blood pressure [5]. Similar results were also observed in two other cohort studies $[7,35]$, in both of which total testosterone, but not free testosterone, was associated with the incidence of diabetes. There is also evidence that the relationship between free testosterone and diabetes is confounded by total body fat or abdominal fat $[9,13]$. Similarly, we also found that the relationship between prediabetes and free testosterone was confounded by general or central obesity. The finding that prediabetes or diabetes is significantly associated with total testosterone but not free testosterone may be explained by a mechanism associated with SHBG. SHBG has been traditionally considered a protein which binds and transports sex steroids and regulates circulating concentrations of free-form hormones. However, recent studies showed that low SHBG can predict the future development of type 2 diabetes, independent of the testosterone concentration $[7,35]$. And there is also evidence that mechanisms associated with the SHBG gene is involved in the pathogenesis of type 2 diabetes [36]. As SHBG tightly binds testosterone, which constitutes the largest portion of total testosterone, the low total testosterone in prediabetic or diabetic patients may be simply the consequence of low SHBG. On the other hand, the low SHBG also cause a shift of testosterone from SHBG-bound to free form, which relatively preserves the amount of free testosterone. While the exact mechanism may be complex and involve more factors, the SHBG level, at least in part, explains 
Table 4. Adjusted odds ratios for free testosterone $<6 \mathrm{ng} / \mathrm{dL}$ in multivariate analyses.

\begin{tabular}{|c|c|c|c|c|c|}
\hline & Model 1 & Model 2 & Model 3 & Model 4 & Model 5 \\
\hline & OR & OR & OR & OR & OR \\
\hline Normoglycemia & 1.00 & 1.00 & 1.00 & 1.00 & 1.00 \\
\hline Prediabetes & $\begin{array}{l}1.27 \\
(0.91,1.77)\end{array}$ & $\begin{array}{l}1.27 \\
(0.91,1.78)\end{array}$ & $\begin{array}{l}1.26 \\
(0.90,1.76)\end{array}$ & $\begin{array}{l}1.20 \\
(0.85,1.68)\end{array}$ & $\begin{array}{l}1.25 \\
(0.89,1.76)\end{array}$ \\
\hline Diabetes & $\begin{array}{l}1.28 \\
(0.81,2.00)\end{array}$ & $\begin{array}{l}1.28 \\
(0.81,2.01)\end{array}$ & $\begin{array}{l}1.25 \\
(0.79,1.98)\end{array}$ & $\begin{array}{l}1.15 \\
(0.72,1.83)\end{array}$ & $\begin{array}{l}1.23 \\
(0.76,1.99)\end{array}$ \\
\hline \multicolumn{6}{|l|}{$\mathrm{FPG}(\mathrm{mg} / \mathrm{dL})$} \\
\hline$<100$ & 1.00 & 1.00 & 1.00 & 1.00 & 1.00 \\
\hline $100-125$ & $\begin{array}{l}1.04 \\
(0.72,1.51)\end{array}$ & $\begin{array}{l}1.04 \\
(0.71,1.51)\end{array}$ & $\begin{array}{l}1.01 \\
(0.69,1.47)\end{array}$ & $\begin{array}{l}0.97 \\
(0.66,1.41)\end{array}$ & $\begin{array}{l}0.97 \\
(0.65,1.45)\end{array}$ \\
\hline $\begin{array}{l}>=126 \text { or } \\
\text { known DM }\end{array}$ & $\begin{array}{l}1.07 \\
(0.67,1.71)\end{array}$ & $\begin{array}{l}1.07 \\
(0.66,1.71)\end{array}$ & $\begin{array}{l}1.04 \\
(0.65,1.67)\end{array}$ & $\begin{array}{l}0.96 \\
(0.59,1.55)\end{array}$ & $\begin{array}{l}0.99 \\
(0.59,1.63)\end{array}$ \\
\hline \multicolumn{6}{|l|}{ PPG (mg/dL) } \\
\hline$<140$ & 1.00 & 1.00 & 1.00 & 1.00 & 1.00 \\
\hline $140-199$ & $\begin{array}{l}1.41 \\
(0.97,2.04)\end{array}$ & $\begin{array}{l}1.41 \\
(0.97,2.04)\end{array}$ & $\begin{array}{l}1.41 \\
(0.97,2.04)\end{array}$ & $\begin{array}{l}1.34 \\
(0.92,1.95)\end{array}$ & $\begin{array}{l}1.39 \\
(0.96,2.02)\end{array}$ \\
\hline $\begin{array}{l}>=200 \text { or } \\
\text { known DM }\end{array}$ & $\begin{array}{l}1.25 \\
(0.80,1.95)\end{array}$ & $\begin{array}{l}1.24 \\
(0.80,1.95)\end{array}$ & $\begin{array}{l}1.23 \\
(0.79,1.93)\end{array}$ & $\begin{array}{l}1.17 \\
(0.74,1.84)\end{array}$ & $\begin{array}{l}1.21 \\
(0.76,1.92)\end{array}$ \\
\hline \multicolumn{6}{|l|}{ HbA1c (\%) } \\
\hline$<5.7$ & 1.00 & 1.00 & 1.00 & 1.00 & 1.00 \\
\hline $5.7-6.4$ & $\begin{array}{l}1.23 \\
(0.89,1.72)\end{array}$ & $\begin{array}{l}1.23 \\
(0.88,1.72)\end{array}$ & $\begin{array}{l}1.21 \\
(0.86,1.69)\end{array}$ & $\begin{array}{l}1.16 \\
(0.83,1.62)\end{array}$ & $\begin{array}{l}1.21 \\
(0.86,1.69)\end{array}$ \\
\hline $\begin{array}{l}>=6.5 \text { or known } \\
\text { DM }\end{array}$ & $\begin{array}{l}1.07 \\
(0.68,1.71)\end{array}$ & $\begin{array}{l}1.08 \\
(0.67,1.72)\end{array}$ & $\begin{array}{l}1.05 \\
(0.65,1.68)\end{array}$ & $\begin{array}{l}0.96 \\
(0.60,1.55)\end{array}$ & $\begin{array}{l}1.01 \\
(0.62,1.66)\end{array}$ \\
\hline \multicolumn{6}{|c|}{ FPG: fasting plasma glucose; PPG: postprandial plasma glucose } \\
\hline $\begin{array}{l}\text { Model 1: adjuste } \\
\text { age and waist } \\
\text { componentsMod } \\
\text { doi: } 10.1371 / \text { jour }\end{array}$ & $\begin{array}{l}\text { d for ageMod } \\
\text { circumference } \\
\text { el 5: adjusted } \\
\text { nal.pone. } 0074\end{array}$ & $\begin{array}{l}\text { el 2: adjusted } \\
\text { Model 4: adj } \\
\text { for age and } \mathrm{N} \\
173.004\end{array}$ & $\begin{array}{l}\text { for age and } \\
\text { usted for ag } \\
\text { hetS }\end{array}$ & $\begin{array}{l}\text { BMIModel 3: } \\
\text { e and numbe }\end{array}$ & $\begin{array}{l}\text { adjusted for } \\
\text { ers of MetS }\end{array}$ \\
\hline
\end{tabular}

the discrepant levels of total testosterone and free testosterone in men with prediabetes or diabetes.
Table 5. Multiple linear regression assessing the association between total testosterone and prediabetes or diabetes.

\begin{tabular}{|c|c|c|c|c|c|c|}
\hline \multirow{2}{*}{\multicolumn{2}{|c|}{ AdjustmentBeta }} & \multicolumn{3}{|l|}{ Prediabetes } & \multicolumn{2}{|l|}{ Diabetes } \\
\hline & & $95 \% \mathrm{Cl}$ & $\mathbf{P}$ & Beta & $95 \% \mathrm{CI}$ & $\mathbf{P}$ \\
\hline Model 1 & -0.045 & $(-0.063,-0.027)$ & $<0.001$ & -0.068 & $\begin{array}{l}(-0.094 \\
-0.042)\end{array}$ & $<0.001$ \\
\hline Model 2 & -0.036 & $(-0.054,-0.018)$ & $<0.001$ & -0.053 & $\begin{array}{l}(-0.079 \\
-0.028)\end{array}$ & $<0.001$ \\
\hline Model 3 & -0.032 & $(-0.050,-0.014)$ & $<0.001$ & -0.047 & $\begin{array}{l}(-0.073 \\
-0.022)\end{array}$ & $<0.001$ \\
\hline Model 4 & -0.025 & $(-0.043,-0.007)$ & 0.005 & -0.034 & $\begin{array}{l}(-0.060 \\
-0.009)\end{array}$ & 0.009 \\
\hline Model 5 & -0.027 & $(-0.045,-0.008)$ & 0.004 & -0.029 & $\begin{array}{l}(-0.056 \\
-0.001)\end{array}$ & 0.039 \\
\hline
\end{tabular}

The value of total testosterone was log transformed

The effect of preidabetes or diabetes was compared with normoglycemia

Model 1: adjusted for ageModel 2: adjusted for age and BMIModel 3: adjusted for age and waist circumferenceModel 4: adjusted for age and numbers of MetS componentsModel 5: adjusted for age and MetS

doi: 10.1371/journal.pone.0074173.t005

Table 6. Multiple linear regression assessing the association between free testosterone and prediabetes or diabetes.

\begin{tabular}{|c|c|c|c|c|c|c|}
\hline & & Prediabetes & & & Diabetes & \\
\hline Adjustment & t Beta & $95 \% \mathrm{Cl}$ & $\mathbf{P}$ & Beta & $95 \% \mathrm{Cl}$ & $\mathbf{P}$ \\
\hline Model 1 & -0.012 & $(-0.028,0.004)$ & NS & -0.024 & $(-0.047,-0.001)$ & 0.04 \\
\hline Model 2 & -0.010 & $(-0.026,0.007)$ & NS & -0.021 & $(-0.044,0.003)$ & NS \\
\hline Model 3 & -0.008 & $(-0.024,0.008)$ & NS & -0.018 & $(-0.041,0.006)$ & NS \\
\hline Model 4 & -0.004 & $(-0.020,0.012)$ & NS & -0.011 & $(-0.034,0.013)$ & NS \\
\hline Model 5 & -0.005 & $(-0.021,0.012)$ & NS & -0.009 & $(-0.034,0.015)$ & NS \\
\hline
\end{tabular}

The value of free testosterone was log transformed

The effect of preidabetes or diabetes was compared with normoglycemia

Model 1: adjusted for ageModel 2: adjusted for age and BMIModel 3: adjusted for age and waist circumferenceModel 4: adjusted for age and numbers of MetS componentsModel 5: adjusted for age and MetS doi: 10.1371/journal.pone.0074173.t006

The identification of TD in men with prediabetes may have clinical implications. Testosterone replacement therapy (TRT) in hypogonadal men with type 2 diabetes and/or metabolic syndrome improves insulin sensitivity in the short-term [37-40]. It may be of interest to investigate whether hypogonadal men with prediabetes could also benefit from TRT, in terms of improving glucose control and, in a long-term perspective, preventing the future development of overt diabetes. Furthermore, as it has been shown that both prediabetes and low testosterone are independent risk factors for cardiovascular disease and event, and all-cause mortality [41,42], it would be interesting to evaluate whether TRT could decrease the risk of cardiovascular events and mortality in men with both TD and prediabetes. However, it should be noted that the current 
consensus on the guideline is that TRT be considered only in men with both TD and clinical symptoms [43]. In this way, defined by a combination of total testosterone of $<300 \mathrm{ng} / \mathrm{dL}$ and Aging Males' Symptoms (AMS) scale $>=27,14.7 \%$ of the prediabetic men in our dataset (unpublished data) could be considered candidates for TRT.

\section{Conclusions}

Men with prediabetes are at an increased risk of subnormal total testosterone, but not free testosterone. The risk is reduced, but remains significant after adjustment for BMI, waist

\section{References}

1. Kapoor D, Aldred H, Clark S, Channer KS, Jones TH (2007) Clinical and biochemical assessment of hypogonadism in men with type 2 diabetes: correlations with bioavailable testosterone and visceral adiposity. Diabetes Care 30: 911-917. doi:10.2337/dc06-1426. PubMed: 17392552.

2. Dhindsa S, Prabhakar S, Sethi M, Bandyopadhyay A, Chaudhuri A et al. (2004) Frequent occurrence of hypogonadotropic hypogonadism in type 2 diabetes. J Clin Endocrinol Metab 89: 5462-5468. doi:10.1210/jc. 2004-0804. PubMed: 15531498.

3. Grossmann M, Thomas MC, Panagiotopoulos S, Sharpe K, Macisaac RJ et al. (2008) Low testosterone levels are common and associated with insulin resistance in men with diabetes. J Clin Endocrinol Metab 93: 1834-1840. doi:10.1210/jc.2007-2177. PubMed: 18319314.

4. Haffner SM, Shaten J, Stern MP, Smith GD, Kuller L (1996) Low levels of sex hormone-binding globulin and testosterone predict the development of non-insulin-dependent diabetes mellitus in men MRFIT Research Group. Multiple Risk Factor Intervention Trial. Am J Epidemiol 143: 889-897.

5. Oh JY, Barrett-Connor E, Wedick NM, Wingard DL (2002) Endogenous sex hormones and the development of type 2 diabetes in older men and women: the Rancho Bernardo study. Diabetes Care 25: 55-60. doi: 10.2337/diacare.25.1.55. PubMed: 11772901.

6. Stellato RK, Feldman HA, Hamdy O, Horton ES, McKinlay JB (2000) Testosterone, sex hormone-binding globulin, and the development of type 2 diabetes in middle-aged men: prospective results from the Massachusetts male aging study. Diabetes Care 23: 490-494. doi: 10.2337/diacare.23.4.490. PubMed: 10857940

7. Lakshman KM, Bhasin S, Araujo AB (2010) Sex hormone-binding globulin as an independent predictor of incident type 2 diabetes mellitus in men. J Gerontol A Biol Sci Med Sci 65: 503-509. PubMed: 20106959.

8. Wang C, Jackson G, Jones TH, Matsumoto AM, Nehra A et al. (2011) Low testosterone associated with obesity and the metabolic syndrome contributes to sexual dysfunction and cardiovascular disease risk in men with type 2 diabetes. Diabetes Care 34: 1669-1675. doi:10.2337/ dc10-2339. PubMed: 21709300.

9. Grossmann M (2011) Low testosterone in men with type 2 diabetes: significance and treatment. J Clin Endocrinol Metab 96: 2341-2353. doi: 10.1210/jc.2011-0118. PubMed: 21646372.

10. Association AD (2012) Diagnosis and classification of diabetes mellitus. Diabetes care 35 Suppl 1: S64-71

11. Tabák AG, Herder C, Rathmann W, Brunner EJ, Kivimäki M (2012) Prediabetes: a high-risk state for diabetes development. Lancet 379: 2279-2290. doi:10.1016/S0140-6736(12)60283-9. PubMed: 22683128.

12. Yeap BB, Chubb SA, Hyde Z, Jamrozik K, Hankey GJ et al. (2009) Lower serum testosterone is independently associated with insulin resistance in non-diabetic older men: the Health In Men Study. Eur J Endocrinol 161: 591-598. doi:10.1530/EJE-09-0348. PubMed: 19661128.

13. Tsai EC, Matsumoto AM, Fujimoto WY, Boyko EJ (2004) Association of bioavailable, free, and total testosterone with insulin resistance: influence of sex hormone-binding globulin and body fat. Diabetes Care 27: 861-868. doi:10.2337/diacare.27.4.861. PubMed: 15047639.

14. Simon D, Preziosi P, Barrett-Connor E, Roger M, Saint-Paul M et al. (1992) Interrelation between plasma testosterone and plasma insulin in healthy adult men: the Telecom Study. Diabetologia 35: 173-177. doi: 10.1007/BF00402551. PubMed: 1547923.

15. Vermeulen A, Verdonck L, Kaufman JM (1999) A critical evaluation of simple methods for the estimation of free testosterone in serum. J Clin circumference, the number of MetS components, or MetS. After adjustment for MetS, the risk for TD in men with prediabetes is almost equal to that of men with diabetes. The substantially increased risk suggests that testosterone should be measured routinely in men with prediabetes.

\section{Author Contributions}

Analyzed the data: $\mathrm{CHH}$. Wrote the manuscript: $\mathrm{CHH}$. Designed the study: SPL. Collected the data: WCL. Contributed to the Discussion: HJY CYW. Commented on the Manuscript: HJY CYW FSJ JTH YSP.

Endocrinol Metab 84: 3666-3672. doi:10.1210/jc.84.10.3666. PubMed: 10523012.

16. Araujo AB, Esche GR, Kupelian V, O'Donnell AB, Travison TG et al. (2007) Prevalence of symptomatic androgen deficiency in men. J Clin Endocrinol Metab 92: 4241-4247. doi:10.1210/jc.2007-1245. PubMed: 17698901.

17. Araujo AB, O'Donnell AB, Brambilla DJ, Simpson WB, Longcope $C$ et al. (2004) Prevalence and incidence of androgen deficiency in middleaged and older men: estimates from the Massachusetts Male Aging Study. J Clin Endocrinol Metab 89: 5920-5926. doi:10.1210/jc. 2003-031719. PubMed: 15579737.

18. Mulligan T, Frick MF, Zuraw QC, Stemhagen A, McWhirter C (2006) Prevalence of hypogonadism in males aged at least 45 years: the HIM study. Int J Clin Practice 60: 762-769. PubMed: 16846397.

19. Rosenstock J, Klaff LJ, Schwartz S, Northrup J, Holcombe JH et al. (2010) Effects of exenatide and lifestyle modification on body weight and glucose tolerance in obese subjects with and without pre-diabetes. Diabetes Care 33: 1173-1175. doi:10.2337/dc09-1203. PubMed: 20332357.

20. Onat A, Can G, Ciçek G, Ayhan E, Doğan Y et al. (2011) Fasting, nonfasting glucose and HDL dysfunction in risk of pre-diabetes, diabetes, and coronary disease in non-diabetic adults. Acta Diabetol: ([MedlinePgn:]) doi:10.1007/s00592-011-0313-x. PubMed: 21769500.

21. Abdul-Ghani MA, Tripathy D, DeFronzo RA (2006) Contributions of beta-cell dysfunction and insulin resistance to the pathogenesis of impaired glucose tolerance and impaired fasting glucose. Diabetes Care 29: 1130-1139. doi:10.2337/dc05-2179. PubMed: 16644654.

22. Goodman-Gruen D, Barrett-Connor E (2000) Sex differences in the association of endogenous sex hormone levels and glucose tolerance status in older men and women. Diabetes Care 23: 912-918. doi: 10.2337/diacare.23.7.912. PubMed: 10895840.

23. Corona G, Rastrelli G, Balercia G, Lotti F, Sforza A et al. (2012) Hormonal association and sexual dysfunction in patients with impaired fasting glucose: a cross-sectional and longitudinal study. J Sex Med 9: 1669-1680. doi:10.1111/j.1743-6109.2012.02717.x. PubMed: 22489756.

24. Tabák AG, Jokela M, Akbaraly TN, Brunner EJ, Kivimäki M et al. (2009) Trajectories of glycaemia, insulin sensitivity, and insulin secretion before diagnosis of type 2 diabetes: an analysis from the Whitehall II study. Lancet 373: 2215-2221. doi:10.1016/S0140-6736(09)60619-X. PubMed: 19515410.

25. Bergman M (2012) Pathophysiology of prediabetes and treatment implications for the prevention of type 2 diabetes mellitus. Endocrine, 43: 504-13. doi:10.1007/s12020-012-9830-9. PubMed: 23132321.

26. Meyer C, Pimenta W, Woerle HJ, Van Haeften T, Szoke E et al. (2006) Different mechanisms for impaired fasting glucose and impaired postprandial glucose tolerance in humans. Diabetes Care 29: 1909-1914. doi:10.2337/dc06-0438. PubMed: 16873801.

27. Basu R, Barosa C, Jones J, Dube S, Carter R et al. (2013) Pathogenesis of Prediabetes: Role of the Liver in Isolated Fasting Hyperglycemia and Combined Fasting and Postprandial Hyperglycemia. J Clin Endocrinol Metab, 98: E409-17. doi:10.1210/jc. 2012-3056. PubMed: 23345093

28. Saukkonen T, Cederberg H, Jokelainen J, Laakso M, Harkonen $P$ et al. (2011) Limited overlap between intermediate hyperglycemia as defined by $\mathrm{A} 1 \mathrm{C}$. pp. 5.7-6.4\%, impaired fasting glucose, and impaired glucose tolerance. Diabetes care 34: 2314-2316

29. Cavalot F, Petrelli A, Traversa M, Bonomo K, Fiora E et al. (2006) Postprandial blood glucose is a stronger predictor of cardiovascular 
events than fasting blood glucose in type 2 diabetes mellitus, particularly in women: lessons from the San Luigi Gonzaga Diabetes Study. J Clin Endocrinol Metab 91: 813-819. PubMed: 16352690.

30. Hanefeld M, Fischer S, Julius U, Schulze J, Schwanebeck U et al. (1996) Risk factors for myocardial infarction and death in newly detected NIDDM: the Diabetes Intervention Study, 11-year follow-up. Diabetologia 39: 1577-1583. doi:10.1007/s001250050617. PubMed: 8960845.

31. Cavalot F, Pagliarino A, Valle M, Di Martino L, Bonomo K et al. (2011) Postprandial blood glucose predicts cardiovascular events and allcause mortality in type 2 diabetes in a 14-year follow-up: lessons from the San Luigi Gonzaga Diabetes Study. Diabetes Care 34: 2237-2243. doi:10.2337/dc10-2414. PubMed: 21949221.

32. Barr RG, Nathan DM, Meigs JB, Singer DE (2002) Tests of glycemia for the diagnosis of type 2 diabetes mellitus. Ann Intern Med 137: 263-272. doi:10.7326/0003-4819-137-4-200208200-00011. PubMed: 12186517

33. Avogaro A (2011) Postprandial glucose: marker or risk factor? Diabetes Care 34: 2333-2335. doi:10.2337/dc11-1442. PubMed: 21949226.

34. Cichosz SL, Fleischer J, Hoeyem P, Laugesen E, Poulsen PL et al. (2013) Assessment of postprandial glucose excursions throughout the day in newly diagnosed type 2 diabetes. Diabetes Technol Ther 15: 78-83. doi:10.1089/dia.2012.0199. PubMed: 23176177.

35. Laaksonen DE, Niskanen L, Punnonen K, Nyyssönen K, Tuomainen TP et al. (2004) Testosterone and sex hormone-binding globulin predict the metabolic syndrome and diabetes in middle-aged men. Diabetes Care 27: 1036-1041. doi:10.2337/diacare.27.5.1036. PubMed: 15111517.

36. Ding EL, Song Y, Manson JE, Hunter DJ, Lee CC et al. (2009) Sex hormone-binding globulin and risk of type 2 diabetes in women and men. N Engl J Med 361: 1152-1163. doi:10.1056/NEJMoa0804381. PubMed: 19657112.

37. Kapoor D, Goodwin E, Channer KS, Jones TH (2006) Testosterone replacement therapy improves insulin resistance, glycaemic control, visceral adiposity and hypercholesterolaemia in hypogonadal men with type 2 diabetes. Eur J Endocrinol 154: 899-906. doi:10.1530/eje. 1.02166. PubMed: 16728551.

38. Kalinchenko SY, Tishova YA, Mskhalaya GJ, Gooren LJ, Giltay EJ et al. (2010) Effects of testosterone supplementation on markers of the metabolic syndrome and inflammation in hypogonadal men with the metabolic syndrome: the double-blinded placebo-controlled Moscow study. Clin Endocrinol (Oxf) 73: 602-612. doi:10.1111/j. 1365-2265.2010.03845.x. PubMed: 20718771.

39. Jones TH, Arver S, Behre HM, Buvat J, Meuleman E et al. (2011) Testosterone replacement in hypogonadal men with type 2 diabetes and/or metabolic syndrome (the TIMES2 study). Diabetes Care 34: 828-837. doi:10.2337/dc10-1233. PubMed: 21386088

40. Heufelder AE, Saad F, Bunck MC, Gooren L (2009) Fifty-two-week treatment with diet and exercise plus transdermal testosterone reverses the metabolic syndrome and improves glycemic control in men with newly diagnosed type 2 diabetes and subnormal plasma testosterone. J Androl 30: 726-733. doi:10.2164/jandrol.108.007005. PubMed: 19578132.

41. Barr EL, Zimmet PZ, Welborn TA, Jolley D, Magliano DJ et al. (2007) Risk of cardiovascular and all-cause mortality in individuals with diabetes mellitus, impaired fasting glucose, and impaired glucose tolerance: the Australian Diabetes, Obesity, and Lifestyle Study (AusDiab). Circulation 116: 151-157. doi:10.1161/CIRCULATIONAHA. 106.685628. PubMed: 17576864.

42. Laughlin GA, Barrett-Connor E, Bergstrom J (2008) Low serum testosterone and mortality in older men. J Clin Endocrinol Metab 93: 68-75. PubMed: 17911176.

43. Bhasin S, Cunningham GR, Hayes FJ, Matsumoto AM, Snyder PJ et al. (2010) Testosterone therapy in men with androgen deficiency syndromes: an Endocrine Society clinical practice guideline. J Clin Endocrinol Metab 95: 2536-2559. doi:10.1210/jc.2009-2354. PubMed: 20525905. 